Odessa State Environmental University, L'vovskaya str., 15, Odessa, 65016, Ukraine

E-mail: dubrovskayayv@gmail.com

\title{
RELATIVISTIC THEORY OF SPECTRA OF PIONIC AND KAONIC ATOMS: HYPERFINE STRUCTURE, TRANSITION PROBABILITIES FOR NITROGEN
}

\begin{abstract}
A new theoretical approach to energy and spectral parameters of the hadronic (pionic and kaonic) atoms in the excited states with precise accounting for the relativistic, radiation and nuclear effects is applied to the study of radiation parameters of transitions between hyperfine structure components of the pionic and kaonic nitrogen. The advanced data on the probabilities of radiation transitions between components of the hyperfine structure transitions $5 \mathrm{~g}-4 \mathrm{f}, 5 \mathrm{f}-4 \mathrm{~d}$ in the spectrum of pionic nitrogen and $8 \mathrm{k}-7 \mathrm{i}, 8 \mathrm{i}-7 \mathrm{~h}$ in the spectrum of kaonic nitrogen are presented and compared with alternative theoretical data.
\end{abstract}

\section{Introduction}

Our work is devoted to the further application of earlier developed new theoretical approach [1-8] to the description of spectra and different spectral parameters, in particular, radiative transitions probabilities for hadronic (pionic and kaonic) atoms in the excited states with precise accounting for the relativistic, nuclear and radiative effects. As it was indicated earlier [7-12] nowadays investigation of the pionic, kaonic and at whole the exotic hadronic atomic systems represents a great interest as from the viewpoint of the further development of atomic and nuclear spectral theories as creating new tools for sensing the nuclear structure and fundamental hadron-nucleus strong interactions [6-14]. Spectroscopy of hadronic atoms already in the electromagnetic sector is extremely valuable area of research that provide unique data for different areas of physics, including nuclear, atomic, molecular physics, physics of particles, sensor electronic etc. It should be emphasized that the theory of pion spectra of atoms are highly excited, even in the electromagnetic sector (ie short-range strong pion-N interaction neglects little) is extremely complex and at present, despite the known progress remains very poorly developed. It is about the fundamental theoretical problems describing relativistic atoms considering nuclear, radiation effects, and a completely insufficient spectral data for pion atoms. While determining the properties of pion atoms in theory is very simple as a series of $\mathrm{H}$ such models and more sophisticated methods such combination chiral perturbation theory (TC), adequate quantitative description of the spectral properties of atoms in the electromagnetic pion sector (not to mention even the strong interaction sector) requires the development of High-precision approaches, which allow you to accurately describe the role of relativistic, nuclear, radiation QED (primarily polarization electron-positron vacuum, etc.). pion effects in the spectroscopy of atoms.

The most popular theoretical models for pionic and kaonic atoms are naturally based on the using the Klein-Gordon-Fock equation, but there are many important problems connected with accurate accounting for as pion-kaon-nuclear strong interaction effects as QED radiative corrections (firstly, the vacuum polarization effect etc.). This topic has been a subject of intensive theoretical and experimental interest (see [1-16]). The perturbation theory expansion on the physical; parameter aZ is usually used to take into account the radiative QED corrections, first of all, effect of the polarization of electronpositron vacuum etc. This approximation is sufficiently correct and comprehensive in a case of the light pionic atoms, however it becomes incorrect in a case of the heavy atoms with large charge of a nucleus $\mathrm{Z}$.

The more correct accounting of the QED, finite nuclear size and electron-screening effects 
for pionic atoms is also very serious and actual problem to be solved more consistently in comparison with available theoretical models and schemes. At last, a development of the comprehensive theory of hyperfine structure and computing radiative transitions probabilities between its components is of a great interest and importance in a modern theory of the hadronic atom spectra [1-39].

\section{Theory}

The basic topics of our theoretical approach have been earlier presented [3-8,27,28], so here we are limited only by the key elements. The relativistic dynamic of a spinless boson (pion) particle is described by the Klein-Gordon-Fock (KGF) equation. As usually, an electromagnetic interaction between a negatively charged pion and the atomic nucleus can be taken into account introducing the nuclear potential $\mathrm{A}_{v}$ in the $\mathrm{KG}$ equation via the minimal coupling $\mathrm{p}_{v} \rightarrow \mathrm{p}_{v}-\mathrm{qA}_{v}$. Generally speaking, the Klein-Gordon-Fock equation can be rewritten as the corresponding two-component equation :

$$
\left[-\left(\sigma_{3}+i \sigma_{2}\right) \frac{\nabla^{2}}{2 \mu}+\sigma_{3} \mu+\left(\sigma_{3}+i \sigma_{2}\right) V_{o p t}^{(0)}+V_{C}^{(0)}\right] \Psi_{i}=E_{i} \Psi_{i},
$$

where $s_{i}$ are the Pauli spin matrices and

$$
\Psi_{i}=\frac{1}{2}\left(\begin{array}{c}
\left(1+\left(E-V_{C}^{(0)}\right) / \mu\right) \phi_{i} \\
\left(1-\left(E-V_{C}^{(0)}\right) / \mu\right) \phi_{i}
\end{array}\right) .
$$

This equation is equivalent to the stationary Klein-Gordon-Fock equation. The corresponding non-stationary Klein-GordonFock equation can be written as follows:

$$
\mu^{2} c^{2} \Psi(x)=\left\{\frac{1}{c^{2}}\left[i \hbar \partial_{t}+e V_{0}(r)\right]^{2}+\hbar^{2} \nabla^{2}\right\} \Psi(x)
$$

where $\mathrm{c}$ is the speed of light, $h$ is the Planck constant, $m$ is the reduced mass of the pionnuclear system, and $\Psi_{0}(\mathrm{x})$ is the scalar wave function of the space-temporal coordinates. Usually one considers the central potential $\left[\mathrm{V}_{0}(\mathrm{r}), 0\right]$ approximation with the stationary solution:

$$
\Psi(\mathrm{x})=\exp (-\mathrm{iE} t / \hbar) \phi(x)
$$

where $\phi(x)$ is the solution of the equation:

$$
\left\{\frac{1}{c^{2}}\left[E+e V_{0}(r)\right]^{2}+\hbar^{2} \nabla^{2}-\mu^{2} c^{2}\right\} \phi(x)=0
$$

Here $E$ is the total energy of the system (sum of the mass energy $\mathrm{mc}^{2}$ and binding energy $\mathrm{e}_{0}$ ). In principle, the central potential $V_{0}$ is the sum of the following potentials: the electric potential of a nucleus, vacuum-polarization potential. The strong interaction potential can be added below. Generally speaking, an energy of the pionic atomic system can be represented as the following sum:

$$
E \approx E_{K G}+E_{F S}+E_{Q E D}+E_{N},
$$

where $E_{K G}$ is the energy of a pion in a nucleus $(Z, A)$ with the point-like charge, $E_{F S}$ is the contribution due to the nucleus finite size effect, $E_{V P}$ is the radiation QED correction, $E_{N}$ is the energy shift due to the strong (pion- or kaon- nuclear) interaction $V_{N}$. In principle, the central potential $V_{0}$ should include the central Coulomb potential, the radiative (in particular, vacuum-polarization) potential as well as the electron-screening potential in the atomicoptical (electromagnetic) sector. Surely, the full solution of the pionic atom energy especially for the low-excited state requires an inclusion the hadron-nuclear strong potential.

The next step is accounting the nuclear finite size effect or the Breit-Rosenthal-CrawfordSchawlow one. In order to do it we use the widespread Gaussian model for nuclear charge distribution. The advantages of this model in comparison with usually used models such as for example an uniformly charged sphere model and others had been analysed in Ref. [3]. Usually the Gauss model is determined as follows:

$$
\rho(r \mid R)=\left(4 \gamma^{3 / 2} / \sqrt{\pi}\right) \exp \left(-\gamma r^{2}\right)
$$

where $\gamma=4 \pi / R^{2}, \mathrm{R}$ is an effective radius of a nucleus.

In order to take into account very important radiation QED effects we use the radiative potential from the Flambaum-Ginges theory [15]. In includes the standard Ueling-Serber 
potential and electric and magnetic form-factors plus potentials for accounting of the high order QED corrections such as:

$$
\begin{gathered}
\Phi_{r a d}(r)=\Phi_{U}(r)+\Phi_{g}(r)+\Phi_{f}(r)+. \\
+\Phi_{l}(r)+\frac{2}{3} \Phi_{U}^{\text {high-order }}(r)
\end{gathered}
$$

where

$$
\begin{gathered}
\Phi_{U}^{\text {high-order }}(r)=-\frac{2 \alpha}{3 \pi} \Phi(r) \frac{0.092 Z^{2} \alpha^{2}}{1+\left(1.62 r / r_{C}\right)^{4}} . \\
\Phi_{l}(r)=-\frac{B(Z)}{e} Z^{4} \alpha^{5} m c^{2} e^{-Z r / a_{B}}
\end{gathered}
$$

Here $e-$ a proton charge and universal function $B(Z)$ is defined by expression: $B(Z)=0.074+0.35 Z$ a.

At last to take into account the electron screening effect we use the standard procedure, based on addition of the total interaction potential SCF potential of the electrons, which can be determined within the Dirac-Fock method by solution of the standard relativistic Dirac equations. It should be noted however, that contribution of theses corrections is practically zeroth for the pionic nitrogen, however it can be very important in transition to many-electron as a rule heavy hadronic atoms.

Further in order to calculate probabilities of the radiative transitions between energy level of the pionic atoms we have used the well-known relativistic energy approach (c. g.[16-28]). Other details are in Refs. $[4,7,8]$.

\section{Results and conclusions}

As example of application of the presented approach, in table 1 we present the data on radiative transition probabilities (in $\mathrm{s}^{-1}$ ) for hyperfine transitions $5 \mathrm{~g}-4 \mathrm{f}$ in the spectrum of the pion nitrogen): Th1- data by TrassinelliIndelicato; Th2- our data.
Table 1.

The radiative transition probabilities (in $\mathrm{s}^{-1}$ ) for hyperfine transitions $5 \mathrm{~g}-4 \mathrm{f}$ in the spectrum of the pion nitrogen: Th1- data by Trassinelli-Indelicato; Th2- our data

\begin{tabular}{|c|c|c|}
\hline F-F & T.I : P (5g-4f) & T.II : P $(5 \mathrm{~g}-4 \mathrm{f})$ \\
\hline $5-4$ & $7.13 \times 10^{13}$ & $7.04 \times 10^{13}$ \\
\hline $4-3$ & $5.47 \times 10^{13}$ & $5.41 \times 10^{13}$ \\
\hline $4-4$ & $5.27 \times 10^{13}$ & $5.23 \times 10^{13}$ \\
\hline $3-2$ & $4.17 \times 10^{13}$ & $4.12 \times 10^{13}$ \\
\hline $3-3$ & $0.36 \times 10^{13}$ & $0.34 \times 10^{13}$ \\
\hline $3-4$ & $0.01 \times 10^{13}$ & $0.009 \times 10^{13}$ \\
\hline
\end{tabular}

In theory by Trassinelli-Indelicato (look, for example, [6]) it has been used the standard atomic spectroscopy amplitude scheme when the transitions energies and probabilities are calculated in the known degree separately. At the same time this computing within the relativistic energy approach is performed more correctly and self-consistently (look details in [4,9] and Refs. therein).

In table 2 we present our data for radiative transition probabilities (in $\mathrm{s}^{-1}$ ) for hyperfine transitions $5 \mathrm{f}-4 \mathrm{~d}$ in the spectrum of the pionic nitrogen: our data.

In table 3 we present the data on radiative transition probabilities (in $\mathrm{s}^{-1}$ ) for the hyperfine transitions $8 \mathrm{k}-7 \mathrm{i}$ in the spectrum of the kaonic nitrogen atom: Th1- the data by TrassinelliIndelicato; Th2 - our data.

Table 2.

Radiative transition probabilities $\left(\mathrm{s}^{-1}\right)$ for hyperfine transitions $5 \mathrm{f}-4 \mathrm{~d}$ in the spectrum of the pioniv nitrogen: our data

\begin{tabular}{|c|c|}
\hline F-F & $\begin{array}{c}\text { Our data } \\
(5 \mathrm{f}-4 \mathrm{~d})\end{array}$ \\
\hline $4-3$ & $4.57 \times 10^{13}$ \\
\hline $3-2$ & $3.16 \times 10^{13}$ \\
\hline $3-3$ & $2.98 \times 10^{13}$ \\
\hline $2-1$ & $2.13 \times 10^{13}$ \\
\hline $2-2$ & $2.25 \times 10^{13}$ \\
\hline $2-3$ & $0.01 \times 10^{13}$ \\
\hline
\end{tabular}


Table 3.

The radiative transition probabilities (in $\mathrm{s}^{-1}$ ) for the $8 \mathrm{k}-7 \mathrm{i}$ transition in the $\mathrm{k}-\mathrm{N}$ atom: Th1- Trassinelli-Indelicato; Th2- our data

\begin{tabular}{|c|c|c|}
\hline F-F' & TI, P & T.II: our data \\
\hline $8-7$ & $1.54 \times 10^{13}$ & $1.51 \times 10^{13}$ \\
\hline $7-6$ & $1.33 \times 10^{13}$ & $1.32 \times 10^{13}$ \\
\hline $7-7$ & $1.31 \times 10^{13}$ & $1.29 \times 10^{13}$ \\
\hline $6-5$ & $1.15 \times 10^{13}$ & $1.12 \times 10^{13}$ \\
\hline $6-6$ & $0.03 \times 10^{13}$ & $0.02 \times 10^{13}$ \\
\hline $6-7$ & $0.00 \times 10^{13}$ & $0.004 \times 10^{13}$ \\
\hline
\end{tabular}

In table 4 we present our data for radiative transition probabilities (in $\mathrm{s}^{-1}$ ) for hyperfine transitions $8 \mathrm{i}-7 \mathrm{~h}$ in the spectrum of the kaonic nitrogen: our data. In whole, the computed radiative transition probabilities values for considered transitions between hyperfine structure components in the spectrum of the pion within theory by Trassinelli-Indelicato and ours demonstrate physically reasonable agreement, however our values are a little lower.

This circumstance fact can be reasonably explained by difference in the computing schemes and different level of accounting for nuclear finite size, QED and other effects (c.g. $[1-3,20,21])$. In any case the data obtained can be considered as sufficiently accurate ones and used in the corresponding applications, indicated in the introduction.

Radiative transition probabilities (in $\mathrm{s}^{-1}$ ) for hyperfine transitions $8 \mathrm{i}-7 \mathrm{~h}$ in spectrum of the kaonic nitrogen: our data

\begin{tabular}{|c|c|}
\hline F-F' & $\begin{array}{c}\text { Our data } \\
(8 \mathrm{i}-7 \mathrm{~h})\end{array}$ \\
\hline $7-6$ & $1.16 \times 10^{13}$ \\
\hline $6-5$ & $0.99 \times 10^{13}$ \\
\hline $6-6$ & $0.96 \times 10^{13}$ \\
\hline $5-4$ & $0.81 \times 10^{13}$ \\
\hline $5-5$ & $0.02 \times 10^{13}$ \\
\hline $5-6$ & $0.005 \times 10^{13}$ \\
\hline
\end{tabular}

\section{References}

1. Khetselius, O.Yu. Relativistic perturbation theory calculation of the hyperfine structure parameters for some heavy-element isotopes. Int. J. Quant. Chem. 2009, 109, 3330-3335.

2. Khetselius, O. Relativistic calculation of the hyperfine structure parameters for heavy elements and laser detection of the heavy isotopes. Phys. Scripta 2009, 135, 014023.

3. Khetselius, O. Hyperfine structure of atomic spectra; Astroprint: Odessa, 2008.

4. Dubrovskaya, Yu., Khetselius, O.Yu., Vitavetskaya, L., Ternovsky, V., Serga, I. Quantum chemistry and spectroscopy of pionic atomic systems with accounting for relativistic, radiative, and strong interaction effects. Adv. in Quantum Chem. 2019, 78, 193-222.

5. Khetselius, O.Yu., Glushkov, A.V., Dubrovskaya, Yu.V., Chernyakova, Yu.G., Ignatenko, A.V., Serga, I.N., Vitavetskaya, L. Relativistic quantum chemistry and spectroscopy of exotic atomic systems with accounting for strong interaction effects. In: Wang YA, Thachuk M, Krems R, Maruani J (eds) Concepts, Methods and Applications of Quantum Systems in Chemistry and Physics. Springer, Cham, 2018; Vol. 31, pp. 71-91.

6. Serga, I.N.; Dubrovskaya, Yu.V.; Kvasikova, A.S.; Shakhman, A.N; Sukharev, D.E. Spectroscopy of hadronic atoms: Energy shifts. $J$. Phys.: Conf. Ser. 2012, 397, 012013.

7. Serga, I.N.; Khetselius, O.Yu.; Vitavetskaya, L.A.; Bystryantseva A.N. Relativistic theory of spectra of pionic atomic systems ${ }^{208} \mathrm{~Pb}$ with account of strong pion-nuclear interaction effects. Photoelectronics. 2017, 26, 68-77.

8. Sukharev, D.E.; Khetselius, O.Yu.; Dubrovskaya, Yu.V. Sensing strong interaction effects in spectroscopy of hadronic atoms. Sensor Electr. and Microsyst. Techn. 2009, N3, 16-21.

9. Khetselius, O.Yu. Quantum structure of electroweak interaction in heavy finite Fermi-systems. Astroprint: Odessa, 2011.

10. Khetselius, O.Y.., Glushkov, A.V., Gurskaya, M.Y., Kuznetsova, A.A., Dubrovs- 
kaya, Yu.V., Serga, I.N., Vitavetskaya, L.A. Computational modelling parity nonconservation and electroweak interaction effects in heavy atomic systems within the nuclearrelativistic many-body perturbation theory. J. Phys.: Conf. Ser. 2017, 905(1), 012029.

11. Batty, C.; Eckhause, M.; Gall, K. et al. Strong interaction effects in high- $\mathrm{Z} \mathrm{K}^{-}$atoms. Phys. Rev. C. 1989, 40, 2154.

12. Erikcson, M.; Ericson, T. Optical Properties of Low Energy Pions in Nuclei. Ann. Phys. 1966, 36, 323.

13. Batty, C J.; Friedman, E.; Gal, A. Saturation effects in pionic atoms and the $\pi^{-}$-nucleus optical potential. Nucl. Phys. A. 1983, 402, 411-428.

14. Indelicato, P. Relativistic effects in fewelectron heavy ions. Ab initio evaluation of levels energy and transitions probabilities. Phys. Scripta 1996, 65, 57.

15. Flambaum, V.; Ginges J. Radiative potential and calculation of QED radiative corrections to energy levels and electromagnetic amplitudes in many-electron atoms. Phys. Rev.A. 2005, 72, 052115.

16. Glushkov A.V., Malinovskaya S.V., Svinarenko A.A., Vitavetskaya L.A., Sensing spectral hierarchy, quantum chaos, chaotic diffusion and dynamical stabilisation effects in a multi- photon atomic dynamics with intense laser field. Sensor Electr. and Microsyst. Techn. 2005, 2(2), 29-35.

17. Mohr, P.J. Quantum Electrodynamics Calculations in few-Electron Systems. Phys. Scripta. 1993, 46, 44.

18. Rusov V., Glushkov A., Vaschenko V., Korchevsky D., Ignatenko A. Stochastic dynamics of the atomic systems in the crossed electric and magnetic field: the rubidium atom recurrence spectra. Bull.of Kiev Nat. Univ.:Ser.Phys.-Math. 2004, N4, 433.

19. Glushkov, A.V. Spectroscopy of cooperative muon-gamma-nuclear processes: Energy and spectral parameters. J. Phys.: Conf. Ser. 2012, 397, 012011.

20. Gubanova, E.R., Glushkov, A.V., Khetselius, O.Yu., Bunyakova, Yu., Buyadzhi, V., Pavlenko, E. New methods in analysis and project management of environmental activity: Electronic and radioactive waste. Kharkiv, FOP, 2017.

21. Khetselius, O.Yu., Lopatkin Yu.M., Dubrovskaya, Yu.V, Svinarenko A.A. Sensing hyperfine-structure, electroweak interaction and parity non-conservation effect in heavy atoms and nuclei: New nuclear-QED approach. Sensor Electr. and Microsyst. Techn. 2010, 7(2), 11-19.

22. Bystryantseva A., Khetselius O.Yu., Dubrovskaya Yu., Vitavetskaya L.A., Berestenko A.G. Relativistic theory of spectra of heavy pionic atomic systems with account of strong pion-nuclear interaction effects: ${ }^{93} \mathrm{Nb}$, ${ }^{173} \mathrm{Yb},{ }^{181} \mathrm{Ta},{ }^{197} \mathrm{Au}$. Photoelectronics. 2016, 25, 56-61.

23. Glushkov, A.V. Relativistic Quantum theory. Quantum mechanics of atomic systems; Astroprint: Odessa, 2008.

24. Kuznetsova A.A., Vitavetskaya L.A., Chernyakova Yu.G., Korchevsky D., Calculating the radiative vacuum polarization contribution to the energy shift of $2 \mathrm{p}-3 \mathrm{~s}$ transition in pionic deuterium. Photoelectronics. 2013, 22, 108-111.

25. Glushkov, A.V.; Khetselius, O.Yu.; Svinarenko, A.A.; Buyadzhi, V.V. Spectroscopy of autoionization states of heavy atoms and multiply charged ions. Odessa: TEC, 2015.

26. Glushkov, A.V. Spectroscopy of atom and nucleus in a strong laser field: Stark effect and multiphoton Resonances. J. Phys.: Conf. Ser. 2014, 548, 012020.

27. Khetselius, O.Yu. Atomic parity non-conservation effect in heavy atoms and observing $\mathrm{P}$ and $\mathrm{PT}$ violation using NMR shift in a laser beam: To precise theory. J. Phys.: Conf. Ser. 2009, 194, 022009.

28. Khetselius, O. Relativistic hyperfine structure spectral lines and atomic parity nonconservation effect in heavy atomic systems within QED theory. AIP Conf. Proc. 2010, 1290, 29-33.

29. Chernyakova, Y.G., Vitavetskaya L., Bashkaryov, P., Serga I., Berestenko, A. The radiative vacuum polarization contribution to the energy shift of some levels of the pionic hydrogen. Photoelectronics 2015, 24, 
122-127.

30. Glushkov, A., Gurskaya, M., Ignatenko, A., Smirnov, A., Serga, I., Svinarenko, A., Ternovsky, E. Computational code in atomic and nuclear quantum optics: Advanced computing multiphoton resonance parameters for atoms in a strong laser field. J. Phys.: Conf. Ser. 2017, 905(1), 012004.

31. Ambrosov S., Ignatenko V., Korchevsky D., Kozlovskaya V. Sensing stochasticity of atomic systems in crossed electric and magnetic fields by analysis of level statistics for continuous energy spectra. Sensor Electr. and Microsyst. Techn. 2005, Issue 2, 19-23.

32. Glushkov, A.V. Relativistic and correlation effects in spectra of atomic systems; Astroprint: 2006.

33. Chernyakova, Y.G., Ignatenko A.V., Vitavetskaya L.A., Sensing the tokamak plasma parameters by means high resolution x-ray theoretical spectroscopy method: new scheme. Sensor Electr. and Microsyst. Techn. 2004, 1, 20-24.

34. Glushkov, A.V., Malinovskaya, S.V., Dubrovskaya, Yu.V., Sensing the atomic chemical composition effect on the beta decay probabilities. Sensor Electr. and Microsyst. Techn. 2005, 2(1), 16-20.

35. Glushkov, A.V., Khetselius, O.Yu., Svina- renko, A.A., Buyadzhi, V.V. Methods of computational mathematics and mathematical physics. P.1. Odessa: TES, 2015.

36. Svinarenko,A.A., Glushkov,A.V.,Khetselius, O.Yu., Ternovsky,V.B., Dubrovskaya, Yu., Kuznetsova, A., Buyadzhi, V. Theoretical spectroscopy of rare-earth elements: spectra and autoionization resonances. Rare Earth Element, Ed. J. Orjuela (InTech) 2017, pp 83-104

37. Glushkov, A.V., Khetselius, O.Yu., Svinarenko A.A., Buyadzhi, V.V., Ternovsky, V.B, Kuznetsova, A., Bashkarev, P Relativistic perturbation theory formalism to computing spectra and radiation characteristics: application to heavy element. Recent Studies in Perturbation Theory, ed. D. Uzunov (InTech) 2017, 131-150.

38. Danilov, V., Kruglyak, Y., Pechenaya, V. Electron density-bond order matrix and the spin density in the restricted CI method. Theor. Chim Acta. 1969, 13(4), 288-296.

39. Glushkov, A.V., Safranov, T.A., Khetselius, O.Yu., Ignatenko, A.V., Buyadzhi, V.V., Svinarenko, A.A. Analysis and forecast of the environmental radioactivity dynamics based on methods of chaos theory: General conceptions. Environm. Problems. 2016, 1(2), 115-120. 
Yu. V. Dubrovskaya, I. N. Serga, Yu. G. Chernyakova, L. A. Vitavetskaya

\section{RELATIVISTIC THEORY OF SPECTRA OF PIONIC AND KAONIC ATOMS: HYPERFINE STRUCTURE, TRANSITION PROBABILITIES FOR NITROGEN}

Summary. A new theoretical approach to energy and spectral parameters of the hadronic (pionic and kaonic) atoms in the excited states with precise accounting for the relativistic, radiation and nuclear effects is applied to the study of radiation parameters of transitions between hyperfine structure components of the pionic and kaonic nitrogen. The advanced data on the probabilities of radiation transitions between components of the hyperfine structure transitions $5 \mathrm{~g}-4 \mathrm{f}, 5 \mathrm{f}-4 \mathrm{~d}$ in the spectrum of pionic nitrogen and $8 \mathrm{k}-7 \mathrm{i}, 8 \mathrm{i}-7 \mathrm{~h}$ in the spectrum of kaonic nitrogen are presented and compared with alternative theoretical data.

Keywords: relativistic theory, hyperfine structure, hadronic atoms

PACS 36.10.-k

Ю. В. Дубровская, И. Н. Серга, Ю. Г. Чернякова, Л. А. Витавецฺкая

\section{РЕЛЯТИВИСТСКАЯ ТЕОРИЯ СПЕКТРОВ ПИОННЫХ И КАОННЫХ АТОМОВ СВЕРХТОНКАЯ СТРУКТУРА, ВЕРОЯТНОСТИ ПЕРЕХОДОВ ДЛЯ АЗОТА}

Резюме. Новый теоретический подход к описанию энергетических и спектральных параметров адронного (пионного и каонного) атомов в возбужденных состояниях с аккуратным учетом релятивистских, радиационных и ядерных эффектов применяется к изучению характеристик радиационных переходов между компонентами сверхтонкой структуры пионного и каонного атомов азота. Представлены уточненные данные о вероятностях радиационных переходов между компонентами сверхтонких структурных переходов 5g-4f, 5f-4d в спектре пионного азота и 8k-7i, 8i-7h в спектре каонного азота, некоторые из которых сравниваются с альтернативными теоретическими данными.

Ключевые слова: релятивистская теория, сверхтонкая структура, адронные атомы

PACS 36.10.-k

Ю. В. Дубровська, І. М. Серга, Ю. Г. Чернякова, Л. А. Вітавецька

\section{РЕЛЯТИВІСТСЬКА ТЕОРІЯ СПЕКТРІВ ПІОННИХ ТА КАОННИХ АТОМІВ: НАДТОНКА СТРУКТУРА, ЙМОВІРНОСТІ ПЕРЕХОДІВ ДЛЯ АЗОТА}

Резюме. Новий теоретичний підхід до опису енергетичних і спектральних параметрів адронних (піонних і каонних) атомів в збуджених станах 3 акуратним урахуванням релятивістських, радіаційних і ядерних ефектів застосовується до вивчення характеристик радіаційних переходів між компонентами надтонкої структури піонного і каонов атомів азоту. Представлені уточнені дані про ймовірності радіаційних переходів між компонентами надтонкої структури, зокрема, переходів 5g-4f, 5f-4d в спектрі піонного азоту і 8k-7i, 8i-7h в спектрі каонного азоту, деякі з яких порівнюються з альтернативними теоретичними даними.

Ключові слова: релятивістська теорія, надтонка структура, адронні атоми 